\title{
www.czasopisma.pan.pl \\ Analysis of Temperature Field, Heat and Fluid Flow of Two-Phase Zone Continuous Casting Cu-Sn Alloy Wire
}

\author{
J. Luo ${ }^{\mathrm{a} *}$, X. Liu ${ }^{\mathrm{a}, \mathrm{b}, \mathrm{c}}, \mathbf{X}$. Wang $^{\mathrm{a}}$ \\ ${ }^{\text {a }}$ School of Materials Science and Engineering, \\ ${ }^{\mathrm{b}}$ State Key Laboratory for Advanced Metals and Materials, \\ ${ }^{c}$ Beijing Laboratory of Metallic Materials and Processing for Modern Transportation, \\ University of Science and Technology Beijing, Beijing 100083, China \\ *Corresponding author. E-mail address: luo_jihui@163.com
}

Received 07.06.2015; accepted in revised form 17.07.2015

\begin{abstract}
$\mathrm{Cu}-4.7 \mathrm{wt}$ \% $\mathrm{Sn}$ alloy wire with $\varnothing 10 \mathrm{~mm}$ was prepared by two-phase zone continuous casting technology, and the temperature field, heat and fluid flow were investigated by the numerical simulated method. As the melting temperature, mold temperature, continuous casting speed and cooling water temperature is $1200{ }^{\circ} \mathrm{C}, 1040^{\circ} \mathrm{C}, 20 \mathrm{~mm} / \mathrm{min}$ and $18{ }^{\circ} \mathrm{C}$, respectively, the alloy temperature in the mold is in the range of $720{ }^{\circ} \mathrm{C}-1081{ }^{\circ} \mathrm{C}$, and the solid/liquid interface is in the mold. In the center of the mold, the heat flow direction is vertically downward. At the upper wall of the mold, the heat flow direction is obliquely downward and deflects toward the mold, and at the lower wall of the mold, the heat flow deflects toward the alloy. There is a complex circular flow in the mold. Liquid alloy flows downward along the wall of the mold and flows upward in the center.
\end{abstract}

Keywords: Two-phase zone continuous casting, $\mathrm{Cu}-\mathrm{Sn}$ alloy, Numerical simulation, Temperature field, Heat flow, Fluid flow

\section{Introduction}

Two-phase zone continuous casting (TZCC) is an advanced technology for compact process to prepare near-net-shape and high performance alloy with infinite length. TZCC alloy has high strength, good ductility, excellent corrosion resistance and conductivity because of microstructure with gains-covered grains [1]. To control the mold temperature is the key factor for TZCC technology. In addition, to further study the TZCC technology and microstructure evolution of TZCC alloy, the temperature field, heat and fluid flow of alloy in the mold should be investigated. The temperature field has a crucial influence on the microstructure of alloy [2-4]. For example, the dendrite growth direction is opposite to heat flow or has a certain angle with heat flow direction $[5,6]$. Generally, the fluid flow in the mold can influence the solute distribution in front of solid/liquid interface, grain growth direction and morphology [7-9]. However, the heat flow in the mold cannot be accurately determined during the TZCC experiment, and there are not methods to actually observe the temperature field and fluid flow of the alloy in the mold. With the development of computer technology, researchers begin using numerical simulation to analysis the complex momentum, mass and heat transfer during the continuous casting. Therefore, it is an effective method to investigate the temperature field, heat and fluid flow of the alloy in the mold [10-12].

In this study, $\mathrm{Cu}-4.7 \mathrm{wt} \% \mathrm{Sn}$ alloy wire with $\varnothing 10 \mathrm{~mm}$ was prepared by TZCC technology, and the preparation process was 
simulated by finite element ProCAST software. The temperature field, heat and fluid flow of $\mathrm{Cu}-4.7$ wt. \% Sn alloy in the mold was investigated.

\section{Experimental}

At present, the $\mathrm{Cu}-4.7$ wt. \% Sn alloy with wide two-phase zone was used as the raw material. Fig.1 shows the schematic diagram of TZCC equipment. The alloy was melted in the graphite crucible, and then fed into the mold through the draft tube. The mold was heated and its temperature was controlled in the range between the liquidus and solidus of the alloy during the continuous casting. The solidified alloy was forced to cool near the exit of the mold, and then it was pulled out of the mold by traction wheels. Fig. 2 is the detailed structure of draft tube, mold and cooling equipment used in TZCC process. The draft tube and the mold were connected together for liquid alloy feeding into mold smoothly from crucible, as shown in Fig. 2(a). The whole structure belonged to central symmetry. The inner diameter of mold was $10 \mathrm{~mm}$. Because of liquid alloy completely feeding into mold, the inner diameter of draft tube was set to $20 \mathrm{~mm}$. In order to independently controlling the mold temperature at the range of two-phase zone of alloy, two insulating grooves were designed to avoid the influence of heating and cooling on the mold. Fig. 2(b) is the structure of cooling equipment, which composed of cooling tube and water-cooled copper sleeve. The inner hole with $\varnothing 10$ $\mathrm{mm}$ of cooling tube was centered on the inner hole of mold when assembling. Cooling water flowed into water-cooled copper sleeve to cool the alloy through cooling tube.

The alloy was melted under an Ar atmosphere in a graphite crucible at the temperature of $1200{ }^{\circ} \mathrm{C}$. The mold temperature was controlled at $1040{ }^{\circ} \mathrm{C}$. With the liquid $\mathrm{Cu}-4.7$ wt. \% Sn alloy in the crucible continuously feeding into the mold, the alloy wire was forced to cool by the cooling equipment at the exit of the mold. The cooling water temperature is $18{ }^{\circ} \mathrm{C}$. Then, the $\mathrm{Cu}-4.7$ $\mathrm{wt} \% \mathrm{Sn}$ alloy wire was continuously prepared by traction wheels at speed of $20 \mathrm{~mm} / \mathrm{min}$.

a)

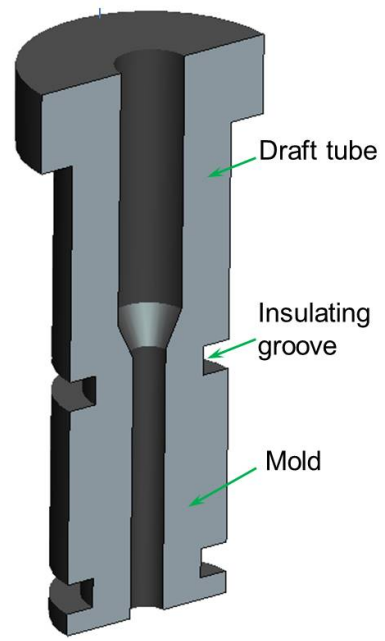

Sample for microstructure observation was cut from the TZCC $\mathrm{Cu}-4.7$ wt. \% Sn alloy wire. After being polished, the sample was etched in a mixture of $\mathrm{FeCl}_{3}(5 \mathrm{~g})$ and alcohol $(80$ $\mathrm{ml}$ ). The microstructure observation was performed by using Nikon Coolpix 995 optical microscope.

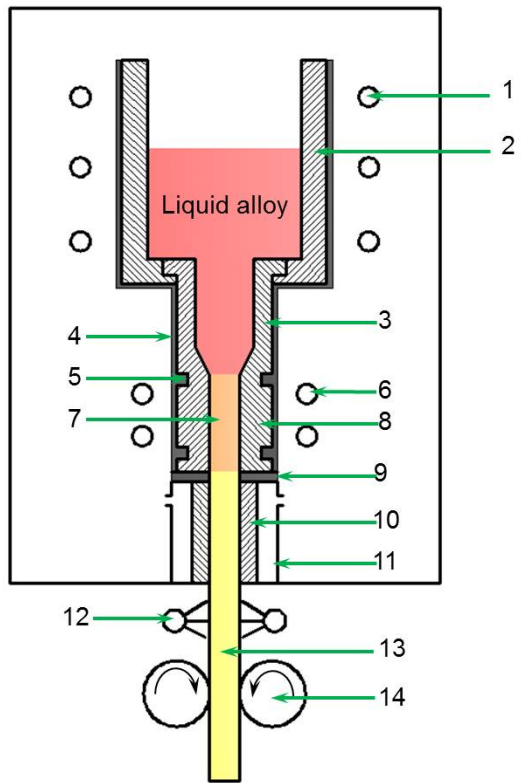

Fig. 1. Schematic diagram of TZCC

1. Induction heating coil; 2. Graphite crucible; 3. Draft tube; 4. Asbestos; 5. Insulating groove; 6. Temperature-controlling induction coil; 7. Two-phase zone; 8. Graphite mold; 9. Heat insulation washer; 10 . Cooling tube 11. Water-cooled copper sleeve 12 . Second cooling water; 13 . Solidified alloy; 14. Traction wheel

Fig. 2. Structure of (a) draft tube, (b) mold and cooling equipment 


\section{Numerical simulation}

\subsection{Simulation software and model}

The ProCAST (Version 2008), which could investigate the temperature field, heat and fluid flow of the alloy, was used as the simulation software [13]. The software provided the database, automatic meshing and visualization tools for variety of solidification technologies.

In order to avoid the influence of cooling equipment on the

a)

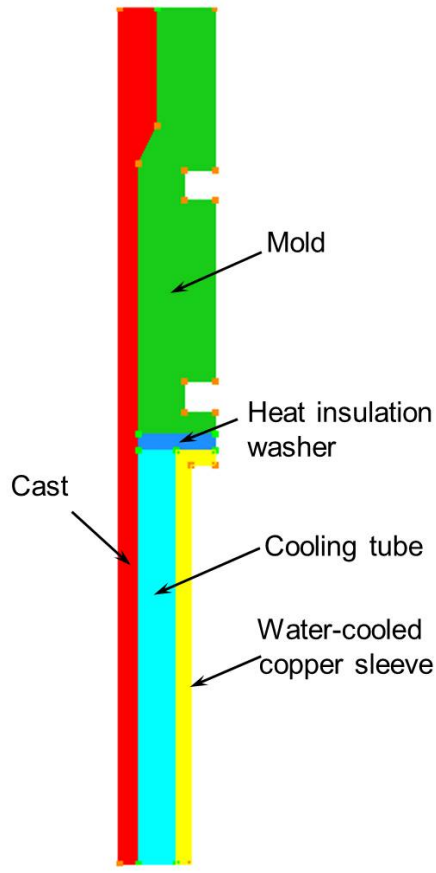

exit temperature of the mold, a heat insulation washer was set between the mold and the cooling equipment. Therefore, the heat flow from mold to cooling equipment was interrupted. Only 2-D axisymmetric model of mold and cooling equipment was built because of the radial structure was completely identical, as shown in Fig. 3(a). The geometric model with same size of the mold and the cooling equipment was created and then meshed in ProCAST software. The model was divided into triangular mesh with maximum edge length of $2 \mathrm{~mm}$, as shown in Fig. 3(b).

b)

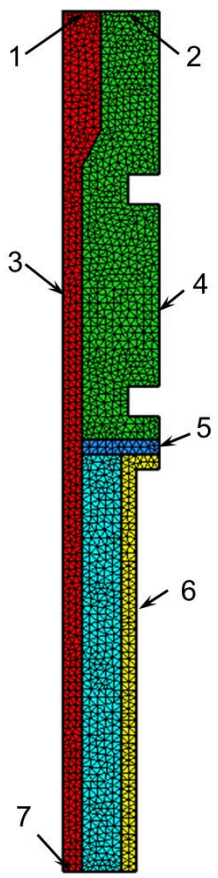

Fig. 3. Illustration of (a) model and (b) mesh

\subsection{Assumptions and boundary conditions}

To simplify the simulation, the following assumptions were established for the TZCC process:

1) Based on the steady-state simulation, only the temperature fields, reaching a steady state under the boundary condition, were considered;

2) Physical parameters, such as heat transfer coefficient, density, etc. were only related with temperature;

3) Cooling water evenly distributed along the circumferential and cooling intensity was identical.

The alloy in the mold was heated by the temperaturecontrolling induction coil while TZCC process performed, and the mold temperature maintained at a constant value which in the two-phase zone range of the alloy. The alloy at the exit mold was cooled by the cooling equipment. Heat insulation washer was set between the mold and the cooling equipment. For insulation, external mold was wrapped by the asbestos. Therefore, the heat transfer between the mold and the protective atmosphere Ar was generally omitted. Considering above the actual heat transfer of TZCC process, corresponding boundary conditions were exerted on the model, as shown in Fig. 3(b).

Boundary 1: Liquid alloy in the draft tube. This interface was set to temperature boundary and the value was the melting temperature of the $\mathrm{Cu}-4.7$ wt. \% Sn alloy;

Boundary 2: This interface was set to temperature boundary and the value was the melting temperature of the $\mathrm{Cu}-4.7$ wt. \% Sn alloy;

Boundary 3: Geometric symmetry axis. This interface was set to adiabatic boundary;

Boundary 4: Outer surface of the mold. This interface was set to temperature boundary and the value was in the temperature range of two-phase zone of $\mathrm{Cu}-4.7 \mathrm{wt}$. $\%$ Sn alloy;

Boundary 5: Edge of the heat insulation washer. This interface was set to adiabatic boundary;

Boundary 6: Cooling surface. The heat transfer (between cooling water and water-cooled copper sleeve) and the temperature were set in accordance with the third 
boundary condition;

Boundary 7: Transverse section of $\mathrm{Cu}-4.7$ wt. \% Sn alloy. After the alloy was cooled in the cooling equipment, the temperature difference in the axial direction was very small on both sides of the border. Therefore, this interface was set to adiabatic boundary.

\subsection{Heat transfer coefficient}

According to the phase diagram of binary $\mathrm{Cu}-\mathrm{Sn}$ alloy, the liquidus temperature of $\mathrm{Cu}-4.7$ wt. $\% \mathrm{Sn}$ is $1050{ }^{\circ} \mathrm{C}$ and the solidus temperature is $920{ }^{\circ} \mathrm{C}$. During the numerical simulation, when the alloy temperature $\mathrm{T}>1050{ }^{\circ} \mathrm{C}$, the alloy is liquid phase, when $920{ }^{\circ} \mathrm{C} \leq \mathrm{T} \leq 1050{ }^{\circ} \mathrm{C}$, the alloy is a two-phase (liquid and solid) zone state, and when $\mathrm{T}<920{ }^{\circ} \mathrm{C}$, the alloy is solid phase. The alloy closely contacted with the mold as the alloy was liquid or two-phase zone state. At this time, the heat transfer between the alloy and the mold was performed by the way of conduction with the large interfacial heat transfer coefficient, According to materials database and heat transfer model of ProCAST, the heat

Table 1.

Width of air gap between mold and TZCC $\mathrm{Cu}-4.7 \mathrm{wt} \% \mathrm{Sn}$ alloy wire

\begin{tabular}{ccccc}
\hline No & Inner diameter of mold / mm & $\begin{array}{c}\text { TZCC alloy diameter / } \\
\mathrm{mm}\end{array}$ & $\begin{array}{c}\text { Width of air gap / } \\
\mathrm{mm}\end{array}$ & $\begin{array}{c}\text { Average width of air gap / } \\
\mathrm{mm}\end{array}$ \\
\hline 1 & 10.02 & 9.96 & 0.03 & 0.033 \\
2 & 9.96 & 9.90 & 0.03 & 0.04 \\
\hline
\end{tabular}

Table 2 .

Width of air gap between cooling tube and TZCC $\mathrm{Cu}-4.7 \mathrm{wt} \% \mathrm{Sn}$ alloy wire

\begin{tabular}{ccccc}
\hline No & $\begin{array}{c}\text { Inner diameter of cooling tube / } \\
\mathrm{mm}\end{array}$ & $\begin{array}{c}\text { TZCC alloy diameter / } \\
\mathrm{mm}\end{array}$ & $\begin{array}{c}\text { Width of air gap / } \\
\mathrm{mm}\end{array}$ & $\begin{array}{c}\text { Average width of air gap / } \\
\mathrm{mm}\end{array}$ \\
\hline 1 & 10.14 & 9.96 & 0.09 & 0.097 \\
2 & 10.08 & 9.90 & 0.09 & 0.11 \\
\hline
\end{tabular}

According to Table 1 and Table 2, the width of air gap between the mold and TZCC Cu-4.7 wt. \% Sn alloy is $0.033 \mathrm{~mm}$, and the width of air gap between the cooling tube and TZCC Cu4.7 wt. \% Sn alloy is $0.097 \mathrm{~mm}$. During the experiment, Ar was used as protective atmosphere. Moreover, based on the thermal coefficient at different temperature of Ar. Heat transfer coefficient between TZCC $\mathrm{Cu}-4.7$ wt. \% Sn alloy and the mold, cooling tube can be calculated according to Eq. (1). The relationship of heat transfer coefficient and temperature is shown in Fig. 4. The blue coefficient between the liquid alloy and the mold was set to 5000 $\mathrm{W} /\left(\mathrm{m}^{2} \cdot \mathrm{K}\right)$. After solidification, air gap developed between the alloy and the mold because of solidification shrinkage. The heat transfer between the alloy and the mold was performed through the air gap [14-16].

The width of air gap was determined by measuring the diameter of TZCC $\mathrm{Cu}-4.7$ wt. \% Sn alloy and the inner diameter of the mold. Consequently, heat transfer coefficient can be calculated as following [17]:

$$
h=\lambda / d
$$

where $h$ is interfacial heat transfer coefficient, $\lambda$ is coefficient of thermal conduction of gas, and $d$ is width of air gap.

The width of air gap between the mold and TZCC $\mathrm{Cu}-4.7$ wt. \% Sn alloy wire was measured, and the results are shown in Table 1. The width of air gap between the cooing tube and TZCC $\mathrm{Cu}-4.7$ wt. \% $\mathrm{Sn}$ alloy wire was measured, and the results are shown in Table 2. curve presents heat transfer coefficient between alloy and mold and the red presents the alloy and cooling tube.

The other heat transfer coefficients were set according to ProCAST software. The heat transfer coefficients between heat insulation washer and alloy, mold, cooling tube and water-cooled copper sleeve were set to $100 \mathrm{~W} /\left(\mathrm{m}^{2} \cdot \mathrm{K}\right)$. The cooling tube closely contacted with the water-cooling copper sleeve, and the heat transfer coefficient between them was set to $2000 \mathrm{~W} /\left(\mathrm{m}^{2} \cdot \mathrm{K}\right)$. 


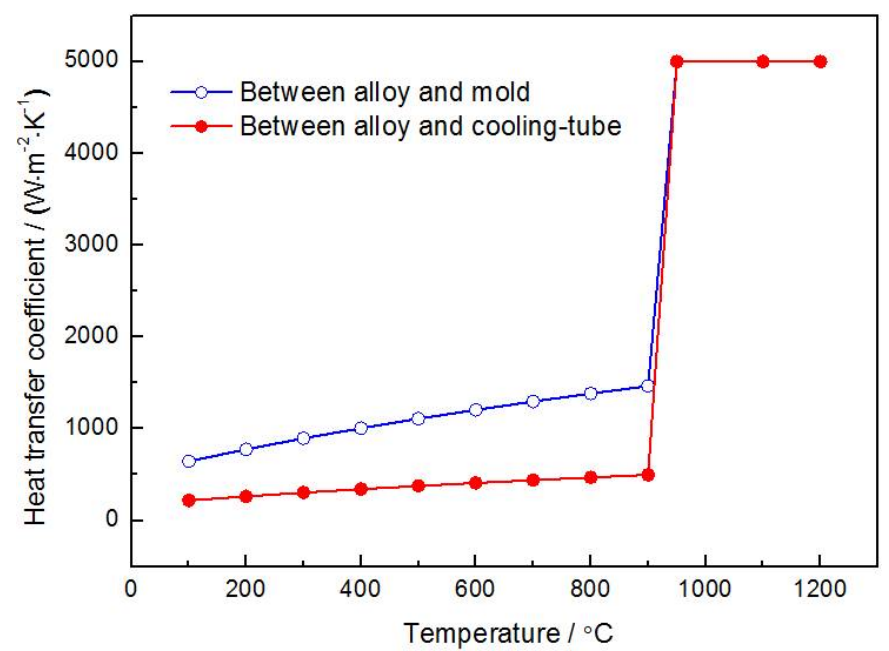

Fig. 4. Relationship between heat transfer coefficient and temperature

\section{Results and discussion}

\subsection{Temperature field simulation results}

The temperature field simulation of integrated model is shown in Fig. 5(a). Fig. 5(b) is the result of temperature field in the mold. The red color area represents the temperature between $1121.3{ }^{\circ} \mathrm{C}-$ $1200.0{ }^{\circ} \mathrm{C}$, the other colors corresponding to the temperature range are shown in the illustration. The temperatures of some location points are marked for specific analysis. From the Fig. 5(b), it can be seen that the mold temperature near the upper insulation groove is $1072{ }^{\circ} \mathrm{C}$, which is lower than the melting temperature. It means that insulation groove plays role of preventing influence of high melting temperature on the mold.
The mold temperature near the lower insulation groove is $1003{ }^{\circ} \mathrm{C}$ and near the middle section is $1037^{\circ} \mathrm{C}$.

From the Fig. 5(b), it also can be seen that the alloy temperature in the mold is between $928^{\circ} \mathrm{C}-1081{ }^{\circ} \mathrm{C}$ (between the upper and lower insulating groove), which meets the temperature range of two-phase (solid and liquid) zone of $\mathrm{Cu}-4.7$ wt. \% $\mathrm{Sn}$ alloy. While the liquid alloy feeds into the mold, the alloy temperature reaches $1081^{\circ} \mathrm{C}$, which is higher than the controlled temperature of the mold. The main reason is that the liquid alloy with high temperature cannot rapidly decrease after feeding into the mold. The alloy temperature near the exit of the mold is between $572^{\circ} \mathrm{C}-838^{\circ} \mathrm{C}$, which has a high temperature gradient with the value of $16^{\circ} \mathrm{C} / \mathrm{mm}$. The alloy temperature is $720^{\circ} \mathrm{C}$ while the alloy completely leaves the mold, thus ensures the $\mathrm{Cu}-$ 4.7 wt. \% Sn alloy to fully solidify. a)

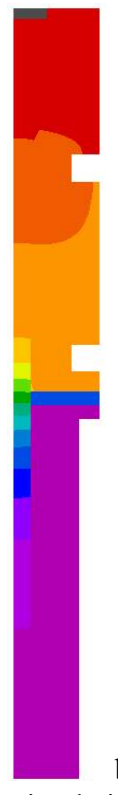

b)

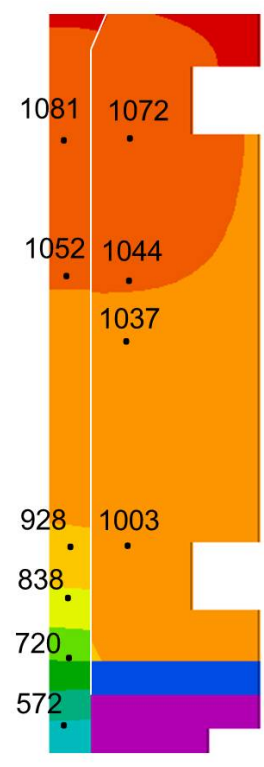

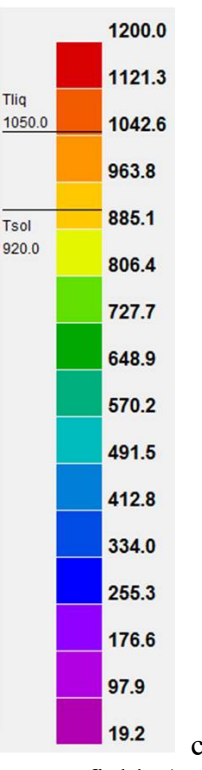

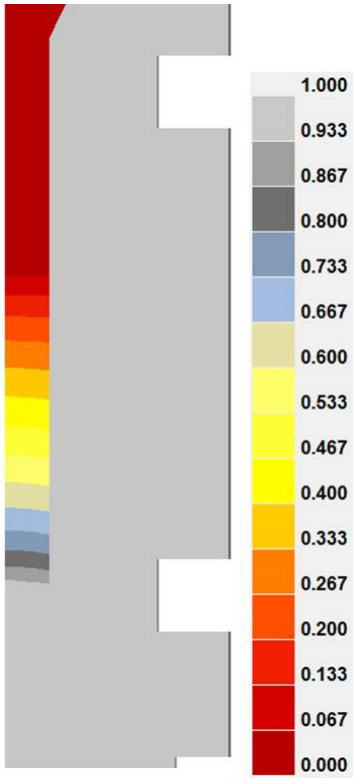

Fig. 5. Simulation results of (a) (b) temperature fields (unit: ${ }^{\circ} \mathrm{C}$ ) and (c) solid/liquid interface 
Fig. 5(c) is the simulation result of solid/liquid interface location of TZCC $\mathrm{Cu}-4.7$ wt. \% Sn. The gray color area represents complete solid phase and the red color represents complete liquid phase. Transition from gray to red color represents the solid and liquid phases both exist area, which belongs to the range of the two-phase zone of the alloy. From the Fig. 5(c), it can be seen that the height of two-phase zone is about $35 \mathrm{~mm}$ and maintains a wide range of two-phase zone. The distance from solid/liquid interface of the alloy to the exit of the mold is about $10 \mathrm{~mm}$.

\subsection{Heat flow simulation results}

The heat flow of the TZCC Cu-4.7 wt. \% Sn alloy in the mold is shown in Fig. 6. The arrows, which present the direction of heat flow, are magnified in order to clearly showing the main heat flow direction. From the Fig. 6, it can be seen that the heat flow direction is vertically downward in the center of the alloy, which parallel to the direction of continuous casting. However, at the edge of the alloy, the heat flow direction is obliquely downward, which have a certain angle with continuous casting direction. The deflection direction is different from upper to lower of the mold. At the upper of the mold, the heat flow direction, which has a certain angle of $1^{\circ}-3^{\circ}$ with continuous casting direction, deflects toward the mold. The main reason is that the temperature of the alloy is higher than that of the mold with the same horizontal position. For instance, the temperature of a point in the alloy is $1052^{\circ} \mathrm{C}$, as shown in Fig. $5(\mathrm{~b})$, and the temperature is $1044^{\circ} \mathrm{C}$ at the mold with same horizontal position. Therefore, there exists horizontal heat flow from the alloy to the mold. In addition, since temperature gradient from the upper to lower of the mold is established during TZCC process, there also exists a strong vertical heat flow parallel to the casting direction. The horizontal and vertical heat flows cause that the heat flow direction at the edge of the alloy is obliquely downward, and deflects toward the mold. At the lower of the mold, the alloy temperature is lower than that of the mold at the same horizontal position. Contrary to depicted above, the heat flow direction at the edge of the alloy deflects toward the alloy.

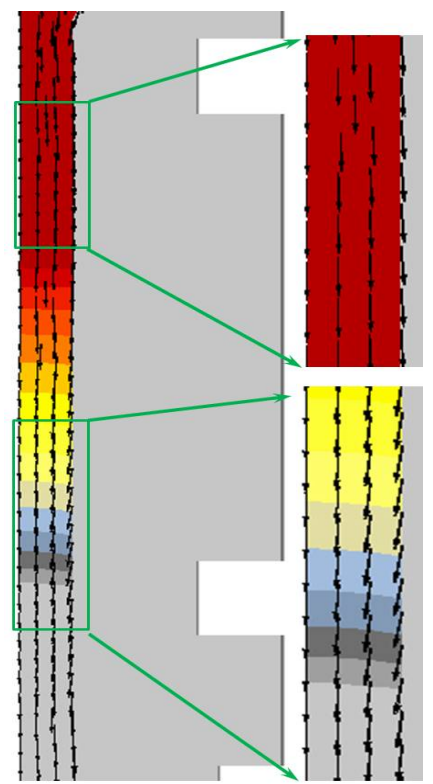

Fig. 6. Heat flow simulation result

\subsection{Fluid flow simulation results}

The fluid flow direction of TZCC $\mathrm{Cu}-4.7$ wt. \% Sn alloy in the mold is shown in Fig. 7. The arrows, which present the fluid flow direction, are magnified in order to clearly showing the main fluid flow direction. At the edge of the mold, the fluid flow is downward along the wall of the mold, which has the same direction of the continuous casting. In the center of the mold, the liquid alloy flows upward. As a result, these two type fluid flow directions cause that the fluid flow of liquid alloy is complicated. In generally, Liquid alloy flows downward along the wall of the mold and flows upward in the center. There are two reasons that caused this phenomenon, one is continuous casting direction, which causes the alloy to flow downward, and the other is convection caused by the temperature difference. From the Fig. 5, it can be seen that the temperature difference exists not only in the alloy from the upper to the lower of the mold, but also between the alloy and the mold. The liquid alloy to flow mutually is mainly attributed to the presence of temperature difference. 


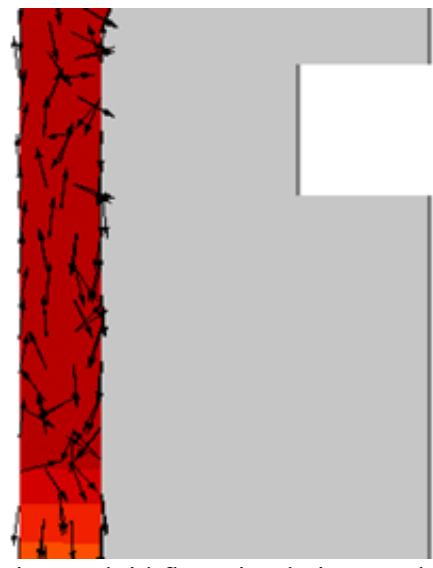

Fig. 7. Fluid flow simulation result

\subsection{Experimental results of $\mathrm{TZCC} \mathrm{Cu}-4.7$ wt. \% Sn alloy wire}

Fig. 8 shows the $\mathrm{Cu}-4.7$ wt. \% Sn alloy wire with $\varnothing 10 \mathrm{~mm}$ prepared by TZCC technology. It can be seen that TZCC $\mathrm{Cu}-4.7$ wt. \% Sn alloy has smooth surface without any obvious defections.

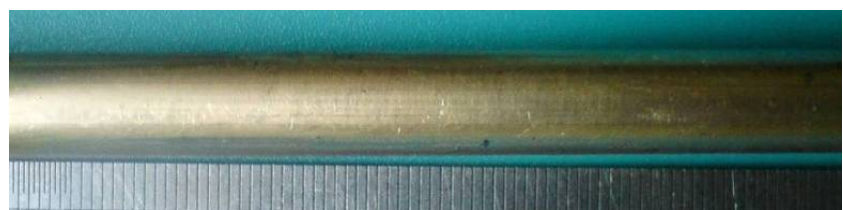

Fig. 8 TZCC $\mathrm{Cu}-4.7$ wt\% $\%$ alloy

Fig. 9 shows the microstructure of the TZCC $\mathrm{Cu}-4.7$ wt. \% Sn alloy. At low magnification observation, the microstructure of the TZCC $\mathrm{Cu}-4.7$ wt. \% $\mathrm{Sn}$ alloy is composed of mainly columnar gains. It can be seen that the vertical columnar grain exist in the center of the alloy and the inclined columnar grain exist at the edge. From the Fig. 6, it can be seen that the heat flow direction is vertically downward in the center of the alloy, thus caused the columnar grain in the center is vertical. However, at the edge of the alloy, the heat flow direction is obliquely downward, which have a certain angle with continuous casting direction. For this reason, the microstructure of inclined columnar grain at the edge of the alloy is formed.

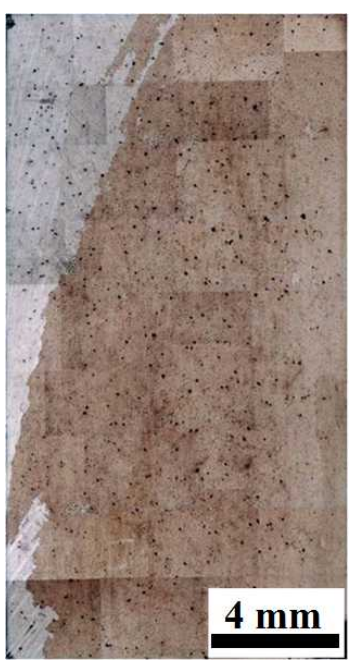

Fig. 9. Microstructure of the TZCC Cu-4.7 wt. \% Sn alloy

\section{Conclusions}

For the $\mathrm{Cu}-4.7$ wt. \% $\mathrm{Sn}$ alloy in the mold in the process of two-phase zone continuous casting (TZCC) at a melting temperature of $1200{ }^{\circ} \mathrm{C}$, mold temperature of $1040{ }^{\circ} \mathrm{C}$, continuous casting speed of $20 \mathrm{~mm} / \mathrm{min}$ and cooling water temperature of $18{ }^{\circ} \mathrm{C}$, the alloy temperature near the upper insulating groove is $1081{ }^{\circ} \mathrm{C}$ and near the lower insulating groove is $928^{\circ} \mathrm{C}$. The alloy temperature is $720{ }^{\circ} \mathrm{C}$ while it completely leaves the mold, and the solid/liquid interface is in the mold. In the center of the mold, the heat flow direction is vertically downward. At the upper wall of the mold, the heat flow direction is obliquely downward and deflects toward the mold, and at the lower wall of the mold, the heat flow deflects toward the alloy. The convection exists in the mold. Liquid alloy flows downward along the wall of the mold and flows upward in the center.

\section{Acknowledgements}

This work was supported by the National Natural Science Foundation of China (51374025), Beijing Natural Science Foundation of China (2152020) and the project of State Key Laboratory for Advanced Metals and Materials of China (2014Z$05)$.

\section{References}

[1] Liu, X., Luo, J., Wang, X., Wang, L. \& Xie, J. (2013). Columnar grains-covered small grains $\mathrm{Cu}-\mathrm{Sn}$ alloy prepared by two-phase zone continuous casting. Progress in Natural Science: Materials International, 23(1): 94-101.

[2] Qu, S., Zhang, Y., Pang, X. \& Gao, K. (2012). Influence of temperature field on the microstructure of low carbon microalloyed ferrite-bainite dual-phase steel during heat treatment. Materials Science and Engineering A, 536. 136- 
142.

[3] Guan, R.G., Zhao, Z.Y., Zhang, Q.S., Lee, C.S. \& Liu, C.M. (2013). Effect of the casting temperature on temperature field and microstructure of A2017 alloy during an innovative continuous semisolid rolling process with a vibrating sloping plate device. The International Journal of Advanced Manufacturing Technology, 67. 917-923.

[4] Zuo, Y., Nagaumi, H. \& Cui. J. (2008). Study on the sump and temperature field during low frequency electromagnetic casting a superhigh strength $\mathrm{Al}-\mathrm{Zn}-\mathrm{Mg}-\mathrm{Cu}$ alloy. Journal of Materials Processing Technology, 197: 109-115.

[5] Zhao, X., Liu, L., Yu, Z., Zhang, W. \& Fu. H. (2010). Microstructure development of different orientated nickelbase single crystal superalloy in directional solidification. Materials Characterization, 61:7-12.

[6] Kato, H. \& Umeda. T. (1978). Growth structures of Al-4.5 wt pct $\mathrm{Cu}$ alloys with dendrite growth directions differing from the heat flow direction. Journal Metallurgical Transactions A, 9: 1795-1800.

[7] Turchin, A.N., Eskin, D.G.\& Katgerman, L. (2005). Effect of melt flow on macro- and microstructure evolution during solidification of an $\mathrm{Al}-4.5 \% \mathrm{Cu}$ alloy. Materials Science and Engineering A, 413-414: 98-104.

[8] Zimmermann, G. Weiss, A. \& Mbaya, Z. (2005). Effect of forced melt flow on microstructure evolution in AlSi7Mg0.6 alloy during directional solidification. Materials Science and Engineering A, 413-414: 236-242.

[9] Henry, S., Gruen, G.U. \& Rappaz. M. (2004). Influence of convection on feathery grain formation in aluminum alloys Metallurgical and Materials Transaction A, 35: 2495-2501.

[10] Janik, M. \& Dyja, H. (2004). Modelling of three-dimensional temperature field inside the mould during continuous casting of steel. Journal of Materials Processing Technology, $157-$ 158: $177-182$.

[11] Eck, S., Kharicha, M.S., Ishmurzin, A. \& Ludwig. A. (2005). Measurement and simulation of temperature and velocity fields during the cooling of water in a die casting model. Materials Science and Engineering A, 413-414: 79-84.

[12] Li, B.Q. (1997). Numerical simulation of flow and temperature evolution during the initial phase of steady-state solidification. Journal of Materials Processing Technology, 71: 402-413.

[13] Lu, S., Xiao, F., Zhang, S., Mao, Y. \& Liao. B. (2014). Simulation study on the centrifugal casting wet-type cylinder liner based on ProCAST. Applied Thermal Engineering, 73: 512-521.

[14] Martorano, M.A. \& Capocchi, J.D.T. (2000). Heat transfer coefficient at the metal-mould interface in the unidirectional solidification of $\mathrm{Cu}-8 \% \mathrm{Sn}$ alloys. International Journal of Heat and Mass Transfer, 43: 2541-2552.

[15] Trovant, M. Argyropoulos. S. (2000). Finding boundary conditions: a coupling strategy for the modeling of metal casting processes: part I. experimental study and correlation development. Metallurgical and Materials Transaction B, 31: 75-86.

[16] Trovant, M. \& Argyropoulos, S. (2000). Finding boundary conditions: a coupling strategy for the modeling of metal casting processes: part II. numerical study and analysis. Metallurgical and Materials Transaction B, 31: 87-96.

[17] Şahin, H.M., Kocatepe, K., Kayıkc1, R. Akar. N. (2006). Determination of unidirectional heat transfer coefficient during unsteady-state solidification at metal casting-chill interface. Energy Conversion and Management, 47: 19-34. 